\title{
Seasonal Incidence of Diabetes Mellitus
}

\author{
D. R. GAMBLE,* M.B., M.C.PATH., DIP.BACT.; K. W. TAYLOR, $†$ M.D., PH.D.
}

Summary : A seasonal incidence in the onset of insulindependent diabetes in patients under 30 years of age has been suggested from the analysis of data derived from the clinic registers of two diabetic clinics. The increased incidence occurred in summer, autumn, and winter, with a peak in the autumn. A significant variation in annual totals of new cases of diabetes seen could not be demonstrated or excluded, but the pattern of the variation present showed significant positive correlation with the annual prevalence data for Coxsackie virus type B4, but not for other types of virus infection.

\section{Introduction}

As long ago as 1926 Adams reported that the onset of acute juvenile diabetes seen in Minnesota, U.S.A., showed a pronounced seasonal pattern, with a peak in September and the lowest incidence in May and June. He attributed this to the sedentary life and respiratory infections of winter, but Spencer (1928), in a small series, found the highest incidence between April and September and concluded that winter infections were not an important factor. Danowski (1957) reported a series of 409 cases of juvenile diabetes which showed a slight winter prevalence but did not convincingly show a seasonal incidence either in month of onset of symptoms or in month of diagnosis.

Diseases with a seasonal incidence are of ten caused by infection. Since there is some evidence to suggest that viral infection may play a part in the production of diabetes (Gamble, Kinsley, FitzGerald, Bolton, and Taylor, 1969), it is important to know whether a seasonal variation in incidence occurs. Furthermore, if infection is a contributory factor, variation in annual incidence could point to specific infective agents by correlation with their yearly prevalence data. This report describes an investigation into the incidence of diabetes mellitus as seen over a limited period of time in two hospitals and compares the pattern found with variations in the prevalence of Coxsackie $\mathrm{B}$ viruses.

\section{Methods and Results}

\section{Seasonal Incidence}

The date of first attendance at the diabetic department of King's College Hospital was ascertained from the clinic registers for all new diabetic patients seen during the 14 years 1955 to 1968. The patients were referred to this clinic mainly from the south-eastern area of Greater London and its environs. The age distribution of a sample of these patients (Fig. 1) suggested that the approximate onset rates in juvenile and maturity-onset diabetes could be compared by selecting insulin-dependent diabetics under the age of 40 years and non-insulin-dependent diabetics over the age of 40 . The distribution by month of first attendance of 2,816 such patients is shown in Fig. 2. The interval between onset of symptoms and diagnosis was on average about one month for insulin-dependent diabetics,

\footnotetext{
* Director, Public Health and Area Laboratories at West Park Hospital, Epsom, Surrey.

ranging from one week to two months in most cases, but for non-insulin-dependent diabetics this interval was longer and more variable, ranging from one week to several years.

The most pronounced seasonal variation was present in क insulin-dependent diabetics in the age group 0-19 years, in $\vec{\circ}$ which the lowest incidence was in June, with an increase in

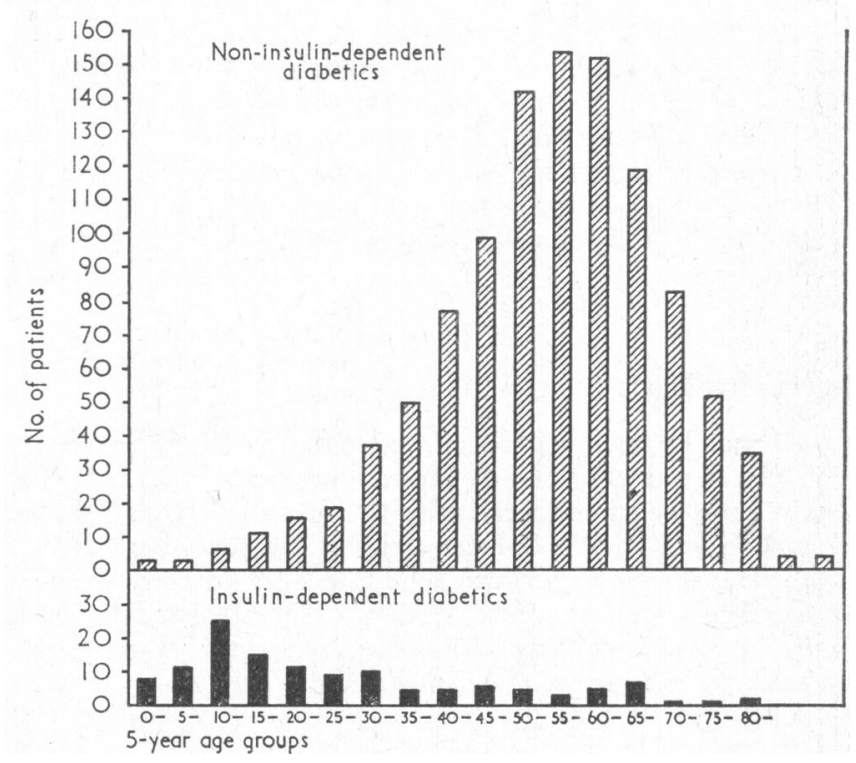

Fig. 1.-Age distribution of 1,186 new cases of diabetes seen at King's College Hospital from 1965 to 1968.

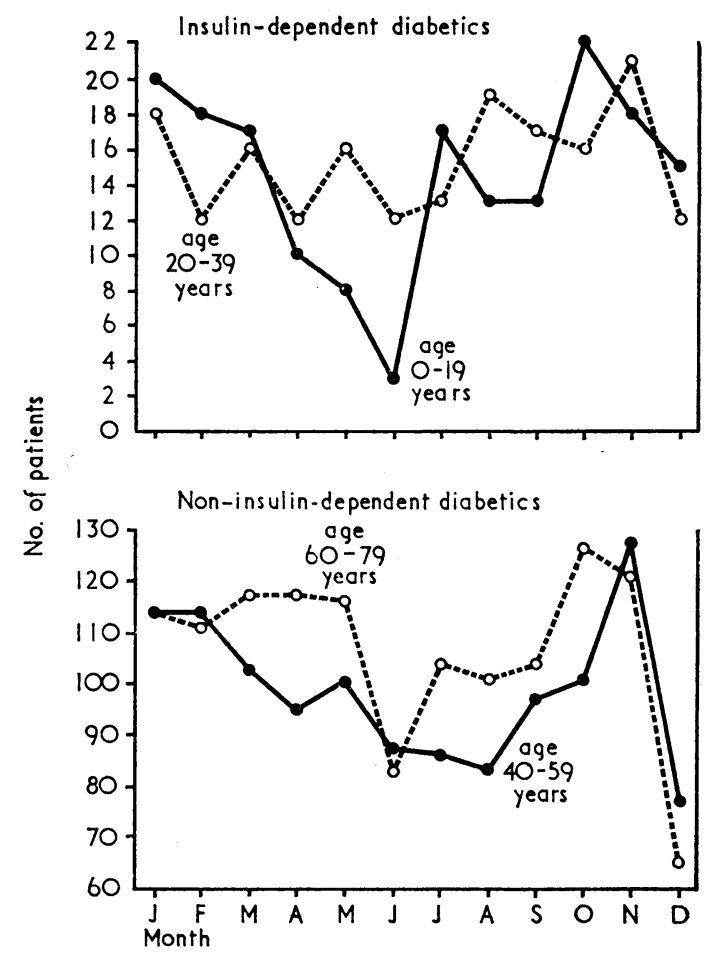

FIG. 2.-Distribution of new cases of diabetes by montn. 
early summer to a broad peak about October. There was then a progressive decline in incidence until the following summer.

Though the seasonal variation in the age group 20-39 years was slight, the pattern was similar, with a broad peak in the autumn. The incidence of non-insulin-dependent diabetes showed less fluctuation, but in general was higher in the winter months than in the summer, except in December, during which there was a sharp fall. This pattern may be the result of patients with mild diabetic symptoms deferring medical consultation over the Christmas holiday period and during the summer months ; the higher winter consultation rate for other illnesses would also tend to produce a winter excess of incidentally diagnosed diabetes.

For the age group 0-19 years quarterly incidence figures for 14 consecutive years were available (Table I). An analysis of variance on these data after square-root transformation ( $\sqrt{\text { age in years }+1})$ showed that the variation between quarters was highly significant $(P<0.001)$.

Similar data were obtained for insulin-dependent diabetics in patients under 30 years of age seen at the General Hospital, Birmingham, during the seven years 1960-6 (Table I). Although full details of all of these patients were not available, a similar seasonal variation was present $(P<0.001)$ but the peak incidence occurred somewhat later in December and January.

\section{Annual Incidence}

The analyses of variance showed that the "between years" variation in numbers of new juvenile diabetics was not significant (Table I) but in both series the probability was less than 0.1 and in the King's College series it fell just short of 0.05 . There was therefore no firm evidence of a marked epidemic pattern during the 14 years' studies. Nevertheless, the possibility of a higher prevalence in some years than others was not excluded by the limited data available.

\section{Coxsackie B virus infection}

In view of the discovery of high Coxsackie B4 virus antibody titres in patients with insulin-dependent diabetes of recent onset (Gamble et al., 1969), the correlation between Coxsackie virus prevalence and annual diabetes incidence was examined. Coxsackie virus prevalence data were derived from the unpublished reports of the Public Health Laboratory Service giving details of viruses isolated in P.H.L.S. and associated laboratories. Few Coxsackie virus isolations were reported before 1958, but steadily increasing numbers have been reported since. A linear regression of the logarithms to the base 10 of virus isolations on year was found to give an adequate fit, the non-linearity being slight in comparison with the fluctuations of yearly virus isolation totals. The differences between the trends of types B1-B5 (Table II) was small in comparison with the deviations from trend and were clearly due to irregularities in size and spacing of epidemics; this similarity of trends suggested that they resulted from expanding virological services rather than increasing virus prevalence. The trend for the totals of all types of Coxsackie B virus was taken as the best trend estimate, and was utilized for determining the deviation from trend for each virus type (Fig. 3). The annual onset figures for diabetics seen at King's College Hospital showed almost no trend, so correlation coefficients were calculated between the crude onset figures and the logarithmic deviations from trend for each virus type (Table II).

TABLE II.-Correlation Between Number of New Cases of fuvenile Diabetes* and Prevalence of Coxsackie B Virusest by Year

\begin{tabular}{|c|c|c|c|c|}
\hline $\begin{array}{l}\text { Coxsackie } \\
\text { Virus } \\
\text { Type }\end{array}$ & $\begin{array}{l}\text { Total } \\
\text { Viruses } \\
\text { Isolated }\end{array}$ & $\begin{array}{l}\text { Regression } \\
\text { of Virus } \\
\text { Isolations } \\
\text { on Year } \neq \\
\text { (b) }\end{array}$ & $\begin{array}{l}\text { Correlation } \\
\text { Coefficient between } \\
\text { Virus Prevalence } \\
\text { and Incidence } \\
\text { of diabetes }(r)\end{array}$ & $\underset{(P)}{\text { Significance }}$ \\
\hline $\begin{array}{c}\text { B1 } \\
\text { B2 } \\
\text { B3 } \\
\text { B4 } \\
\text { B5 } \\
\text { Other types } 6\end{array}$ & $\begin{array}{r}250 \\
1,332 \\
882 \\
918 \\
2,076 \\
179\end{array}$ & $\begin{array}{l}+0.123 \\
+0.129 \\
+0.134 \\
+0.105 \\
+0.051 \\
-\end{array}$ & $\begin{array}{l}-0.158 \\
+0.224 \\
+0.017 \\
+0.723 \\
-0.547 \\
-\end{array}$ & $\begin{array}{l}>0.05 \\
>0.05 \\
>0.05 \\
>0.01 \\
>0.05 \\
>0.05\end{array}$ \\
\hline All types & 5,637 & +0.077 & -0.526 & $>0.05$ \\
\hline
\end{tabular}

- Insulin-dependent diabetics aged 0-19 years seen at King's College Hospital. $t$ Deviations from trend (see text).

$¥ \log 10$ number of viruses isolated by year.

40 type $B 6$ and 139 not typed.

The incidence of Coxsackie B virus infections since 1958 showed different patterns for different virus types. Thus type B5 appeared in two large epidemics separated by five years, while B1 showed small peaks about every other year. B2 and B3 produced intermediate-sized peaks at about four-year intervals and B4 had an irregular pattern with small peaks and intervals.

The most remarkable feature of these data was the similarity between the variations in incidence of Coxsackie B4 infection and the number of new cases of insulin-dependent diabetes seen at King's College Hospital in corresponding years. This was confirmed by the correlation coefficient $(r=+0.723 ; \mathrm{P}<0.02)-$ the only statistically significant coefficient. It must be stressed, however, that this correlation is based on very small numbers of diabetic patients in which a statistically significant variation in annual incidence could not be demonstrated.

TABLE I.-New Cases of Insulin-dependent Diabetes by Quarters

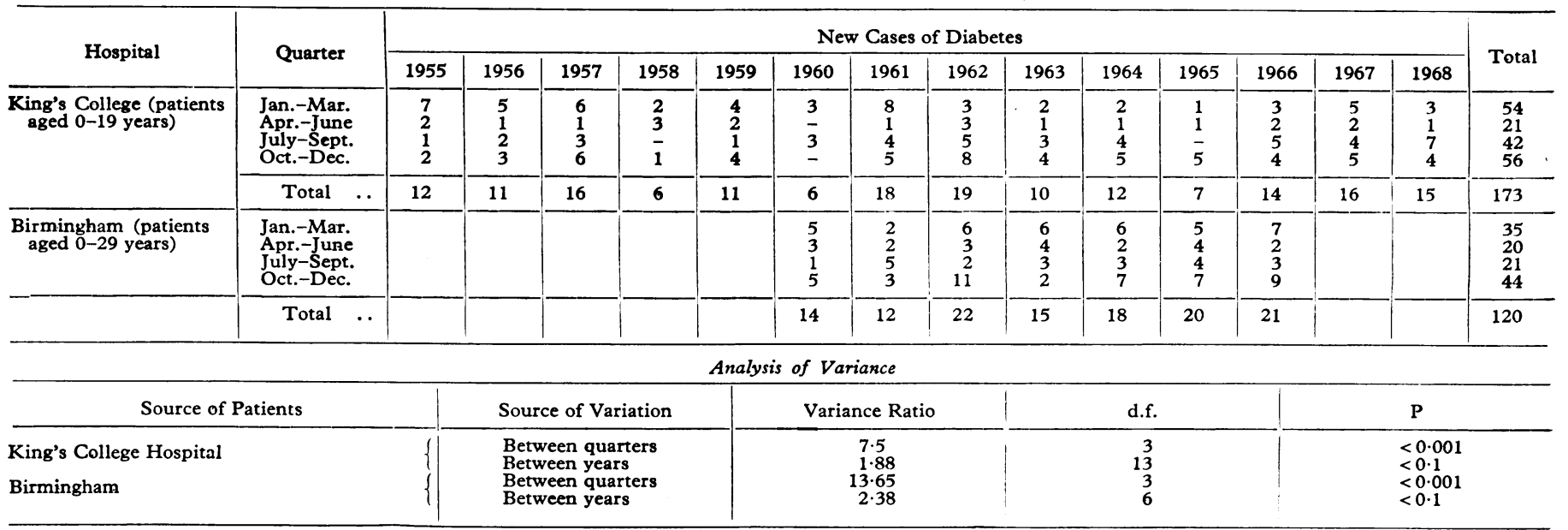


Apart from type B4 the other types did not show significant correlation, and coefficients were either small or negative.

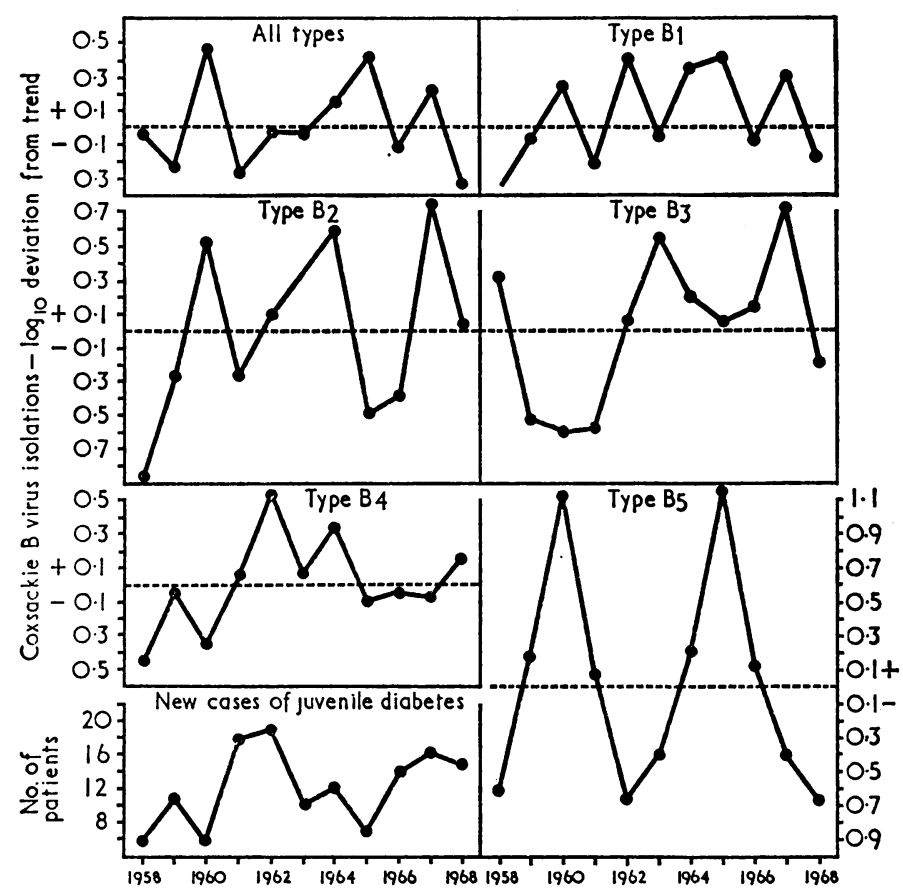

FIG. 3.-Coxsackie B virus prevalence (see text) and number of new cases of juvenile (0-19 years) insulin-dependent diabetes seen at King's College Hospital per year from 1958 to 1968.

\section{Discussion}

The seasonal variation in the numbers of newly diagnosed cases of juvenile diabetes at two diabetic clinics, which are about 100 miles $(160 \mathrm{~km}$.) apart, are similar and highly significant statistically. If allowance of one month is made for the interval between onset of symptoms and diagnosis, our data indicate an increased onset rate between June and March of the following year, with a peak in the autumn, agreeing closely with the pattern reported by Adams (1926). The severity of this type of diabetes is such that deferment of medical consultation during traditional holiday seasons is an unlikely cause of spurious seasonal variation; moreover, the absence of any pronounced fall in onset rate during the peak holiday periods of August and December suggests that it is a genuine variation in the onset of the disease.

This seasonal pattern could arise from a number of causes or a combination of causes, such as climatic factors, dietary changes, obesity, physical activity, and infection, but it is difficult to reconcile the prolonged high incidence in summer, autumn, and winter with the seasonal variations of most of these factors. Adams (1926) suggested that respiratory infections and physical inactivity during winter were responsible, but this could not be so in July and August. Summer and autumn constitute the season of enterovirus infections, but such infec- tions are uncommon during the first six months of the year; a combination of enterovirus and respiratory infection might produce a seasonal pattern of illness similar to the pattern found in onset of diabetes, but we have not found any serological evidence of an excess of recent respiratory virus infection in new juvenile diabetics (Gamble et al., 1969), and others have found no association with clinical respiratory infection (White, 1932 ; Danowski, 1957). Enterovirus infection or some other factor which is present in autumn combined with a variable latent period before development of diabetes could also produce the seasonal pattern found.

Enteroviruses generally vary in prevalence from year to year, as do most of the illnesses they are known to cause-for example, poliomyelitis. Does juvenile diabetes show any such variation in incidence? Our data did not satisfactorily answer this question, but some variation was found. The population at risk was not defined, and numbers of diabetics referred to the two hospitals would doubtless be determined by many factors which might exaggerate or depress fluctuations in the annual numbers of referrals. In these circumstances the yearly totals of new cases might follow a bizarre distribution and the variation might have more significance than formal tests indicate. Real or imaginary, the variation was closely correlated with Coxsackie B4 virus prevalence. The prevalence of other Coxsackie B types was independent of juvenile diabetes onset rates ; moreover, types $\mathrm{B} 2, \mathrm{~B} 3$, and $\mathrm{B} 5$ occurred in big epidemics at intervals of three or more years, which would probably have been reflected in the diabetic onset rates had they been associated.

Diabetes is a disease of multiple aetiology in which genetic, environmental, and endocrine factors play a part (Cerasi and Luft, 1967 ; Pyke and Taylor, 1967 ; Taylor, 1969). The acute form of diabetes is a sudden event, particularly in the young, resembling the diabetes produced in animals by factors known to damage islets. Serum insulin is low at the onset of this type of diabetes, and this was so in many of our patients in whom it was assayed. The abrupt onset is in keeping with the idea that the disease is initiated by a toxic or infective process, followed perhaps by an autoimmune response, and the seasonal variation in incidence suggests that the precipitating factor might be infective rather than toxic.

We would conclude that our results provide further evidence of an association between infection and juvenile diabetes, but the aetiological significance of these findings remains uncertain.

We are grateful to Dr. M. G. FitzGerald and Dr. J. M. Malins, of the General Hospital, Birmingham, for information about patient under their care.

\section{REFERENCES}

Adams, S. F. (1926). Archives of Internal Medicine, 37, 861. Cerasi, E., and Luft, R. (1967). Diabetes, 16, 615.

Danowski, T. S. (1957). Diabetes Mellitus, with Emphasis on Children and Young Adults, p. 129. Baltimore, Williams and Wilkins.

Gamble, D. R., Kinsley, M. L., FitzGerald, M. G., Bolton, R., and Taylor, K.' W. (1969). British Medical Fournal, Golton,

Pyke, D. A., and Taylor, K. W. (1967). British Medical fournal, 4, 21 Pyke, D. A., and Taylor, K. W. (1967). British Medical fournal, 4, 21. Spencer, H. (1928). American fournal of Diseases in Children, 36, 502 Taylor, K. W. (1969). Fournal of Clinical Pathology. In press. hite, $\mathrm{P}$. (1932). Diabetes in Childhood and Adolescence, p. 47. Phila-
delphia, Lea and Febiger. 